\title{
ASSESSMENT OF POTENTIAL DRUG INTERACTIONS AMONG HOSPITALIZED PATIENTS IN NEUROLOGY DEPARTMENT IN TERTIARY CARE HOSPITALS
}

\section{DIJO DAIS ${ }^{1}$, RANJEET AVIS CHERUVATHOOR ${ }^{1}$, KAMESWARAN R ${ }^{1 *}$ SHANMUGA SUNDARAM RAJAGOPAL ${ }^{2}$}

${ }^{1}$ Department of Pharmacy Practice, J.K.K. Nattraja College of Pharmacy, Kumarapalayam, Tamil Nadu, India. ${ }^{2}$ Department of Pharmacology, J.K.K. Nattraja College of Pharmacy, Kumarapalayam, Tamil Nadu, India. Email: kamesjohashwanth@gmail.com

Received: 19 September 2018, Revised and Accepted: 07 January 2019

\section{ABSTRACT}

Objective: This research was instigated to determine and assess the prevalence, severity, type, and the total number of potential drug interactions in the neurology department of two hospitals in India.

Methods: The data were collected from the prescriptions and by patient history interview on a daily basis. The drug-drug interactions (DDIs) were identified using Micromedex ${ }^{\circledast}$ database-2.7 and drugs.com.

Results: The drug interactions were influenced by a plethora of risk factors: Gender, age, comorbidities, length of hospital stay, and the neurological condition. The study was comprised 320 patients, among 196 patients were identified with potential DDIs (PDDIs), and a total of 450 PDDIs were observed. The prevalence of PDDIs according to the severity was major (42.6\%), moderate (45.11\%), and minor (12.22\%).

Conclusion: To lessen PDDIs, the range of medications for the patients must be properly managed, and it is encouraged to remove all medicines without therapeutic advantage, intention, and an indication.

Keywords: Neurology, Drug-drug interactions, Risk factors.

(c) 2019 The Authors. Published by Innovare Academic Sciences Pvt Ltd. This is an open access article under the CC BY license (http://creativecommons. org/licenses/by/4. 0/) DOI: http://dx.doi.org/10.22159/ajpcr.2019.v12i3.29484

\section{INTRODUCTION}

Drug-drug interactions (DDIs) are defined as two or more drugs interacting in such a manner that the effectiveness or toxicity of one or more drugs is altered [1,2]. DDIs are an important subgroup of adverse drug events (ADE) [3] which are highly prevalent in patients receiving multiple-drug treatment [4]. The majority of the interactions occur because either prescriber's do not consider them relevant $[5,6]$ or prescriber may be receiving less information in the DDIs area. Polypharmacy, geriatric, and patients with comorbidities are considered as one of the major risk factors in the precipitation of DDIs [5]. Neurological illnesses are one among the most common causes of hospitalization. It is estimated that DDIs account for approximately $2.8 \%$ of hospital admission every year [6].

The issue of drug interactions is a global concern; a study of the US reported that $30.3 \%$ of patients are at the risk of DDIs [7]. A recent study in Iran has reported that in $35.5 \%$ of the patients in the neurology ward encountered with at least one potential DDIs (PDDIs) [8]. The burden of neurological disorders in India is estimated over 30 million which often warrant complex therapeutic regimen [9]. In India, a study identified $66 \%$ of DDIs in a medical department of a tertiary care hospital in Karnataka, India [10], while another study in Chandigarh reported that $8.3 \%$ prescriptions had multiple DDIs [11]. It was estimated that about $46.3 \%$ of drug interactions were seen in neurological patients in a crosssectional study conducted in Karnataka and the majority of the DDIs were moderate in severity and required therapeutic monitoring [12].

An exhaustive literature search did not reveal as many published reports on DDIs in neurological disorders in Indian population or other countries; however, similar studies in other hospital wards have been done. The present study was instigated to determine the prevalence and assessment of DDIs in patients admitted to the neurology department and to identify PDDIs risk factors. In view of above-mentioned statistics, we purposefully conducted this study in a tertiary care hospital in Erode as there are no studies targeted this region of the country.

\section{METHODS}

The research was a prospective observational study; the work was reviewed and approved by the Institute Ethics Committee (Human Studies), ethics number is JKKNCP/ETHICS_PRACTICE/017PDS05. It was conducted at a tertiary care hospital, Erode, Tamil Nadu, India. The study period was 6 months, with a sample size 320 inpatients. The inclusion criteria were patients with neurological disorders. Both gender of patients, along with 12 years of age with co-morbidities. The prospective study was carried out for a period of 6 months in the neurology department of a tertiary care hospital, Erode.

\section{RESULTS}

A total of 320 inpatients were selected from a neurological department in tertiary care hospitals. It includes the cases of Stroke, Epilepsy, Parkinson's disease, Alzheimer's disease, and its comorbidities. A total number of cases have interaction; drug-drug (196), drug-food (90), and drug-disease (166) and the total number of interactions; drug-drug (450), drug-food (105), and drug-disease (263), respectively (Fig. 1).

In this study, we mainly focused on DDIs. Demographic details of the same are given Tables 1 and 2.

PDDI in males (108) and females (88) shows that most interactions are found in stroke (39.79\%) and least among Alzheimer's disease (2.04\%). Another study [13] reported out of 200 patients, ischemic stroke patients were higher than hemorrhagic stroke.

The most common interacting pair was found to be aspirin+clopidogrelmajor with a frequency of 67 , and the least was found to be amitriptylline+fluoxetine-major (Table 3).

The total number of PDDI and prevalence for 196 out of 320 patients was found to be 450 PDDIs and $42.66 \%$, respectively (Table 4). 
Table 1: Patient demographics

\begin{tabular}{ll}
\hline Parameters & Frequency (\%) \\
\hline Age-wise distribution & \\
$18-30$ & $14(7)$ \\
$31-45$ & $25(13)$ \\
$46-59$ & $33(17)$ \\
$60-70$ & $53(27)$ \\
$>70$ & $71(36)$ \\
Duration of hospital stay & \\
$\leq 3$ & $45(23)$ \\
$4-6$ & $87(44)$ \\
$\geq 7$ & $64(33)$ \\
Number of prescribed medications & \\
$\leq 3$ & $33(17)$ \\
$4-6$ & $68(35)$ \\
$\geq 7$ & $95(48)$ \\
\hline
\end{tabular}

Table 2: Gender-wise distribution of PDDIs

\begin{tabular}{llll}
\hline Disease condition & $\begin{array}{l}\text { Males } \\
(\mathbf{n = 1 0 8 )}\end{array}$ & $\begin{array}{l}\text { Females } \\
(\mathbf{n = 8 8 )}\end{array}$ & $\begin{array}{l}\text { Frequency } \\
\mathbf{n = 1 9 6} \mathbf{( \% )}\end{array}$ \\
\hline Stroke & 40 & 38 & $78(39.79)$ \\
Stroke+Alzheimer's disease & 6 & 3 & $9(4.59)$ \\
Stroke+Parkinson's disease & 3 & 5 & $8(4.08)$ \\
Stroke+Epilepsy & 11 & 10 & $21(10.71)$ \\
Epilepsy & 36 & 21 & $57(29.10)$ \\
Parkinson's disease & 9 & 6 & $15(7.65)$ \\
Alzheimer's disease & 1 & 3 & $4(2.04)$ \\
Others & 2 & 2 & $4(2.04)$ \\
\hline
\end{tabular}

PDDIs: Potential drug-drug interactions

Table 3: Highest PDDI combinations in neurology

\begin{tabular}{llll}
\hline PDDI combination & Type & Severity & $\begin{array}{l}\text { Frequency } \\
\mathbf{n = 4 5 0} \text { (\%) }\end{array}$ \\
\hline Aspirin+clopidogrel & PD & Major & $67(14.88)$ \\
Carbamazepine+phenytoin & PK & Major & $22(4.88)$ \\
Aspirin+metformin & PD & Major & $10(2.22)$ \\
Amlodipine+clopidogrel & PK & Major & $9(2)$ \\
Atorvastatin+clopidogrel & PK & Moderate & $40(8.88)$ \\
Clonazepam+theophylline & PD & Moderate & $9(2)$ \\
Phenytoin+clonazepam & PK & Moderate & $7(1.55)$ \\
Clobazam+carbamazepine & PK & Minor & $22(4.88)$ \\
Amitriptyline+fluoxetine & PK+PD & Major & $5(1.11)$ \\
Diazepam+phenytoin & Unknown & Major & $21(4.66)$ \\
\hline
\end{tabular}

PDDI: Potential drug-drug interaction

Table 4: Prevalence of PDDIs

\begin{tabular}{ll}
\hline Severity of PDDI & Frequency $\mathbf{n = 4 5 0}(\mathbf{\%})$ \\
\hline Major & $192(42.66)$ \\
Moderate & $203(45.11)$ \\
Minor & $55(12.22)$ \\
\hline
\end{tabular}

PDDIs: Potential drug-drug interactions

There were 72 interacting pairs identified during the study. Among 450 PDDIs, 268 (59.55\%) were pharmacokinetic (PK) interactions, 140 (31.13\%) were pharmacodynamic (PD) interactions, 8 (1.77\%) were of both $\mathrm{PK}+\mathrm{PD}$ interactions, and 34 (7.55\%) were unknown interactions (Fig. 2).

Among 268 PK DDIs, 228 (85.07\%) were due to metabolism, 10 (3.75\%) were due to absorption, 7 (2.61\%) were due to distribution, $2(0.74 \%)$ were due to excretion, and $21(7.83 \%)$ were due to both distribution + excretion interactions (Fig. 3).

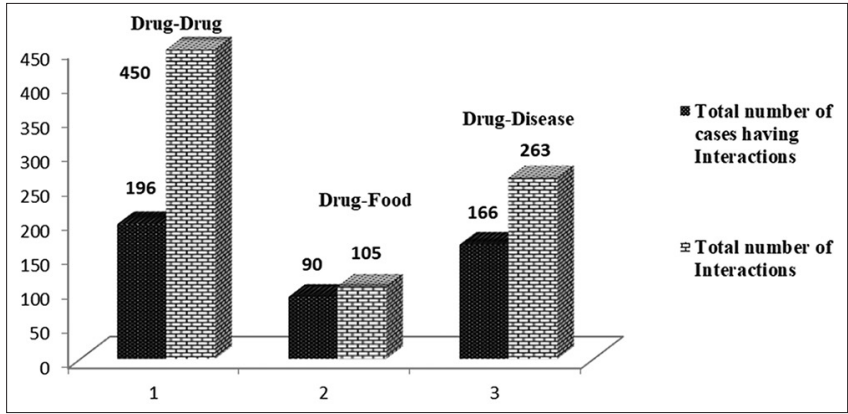

Fig. 1: Distribution of the total number of potential drug interactions

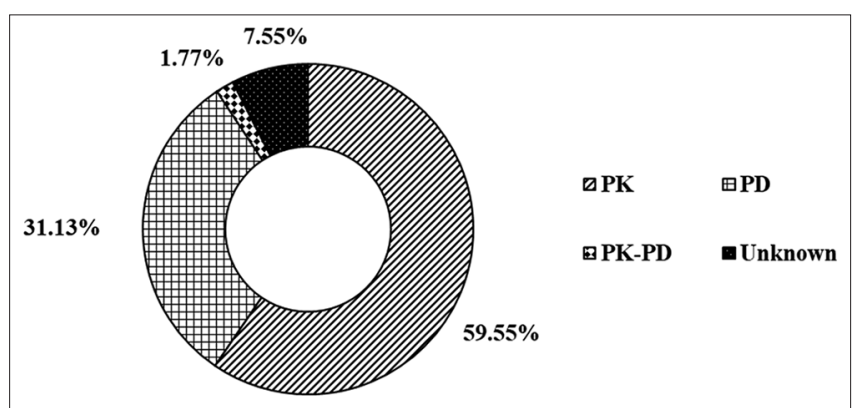

Fig. 2: Types of potential drug-drug interactions

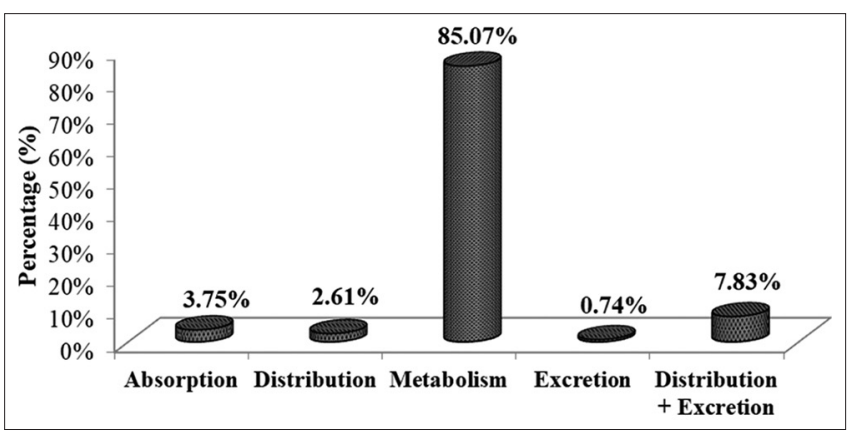

Fig. 3: Type of pharmacokinetic interaction

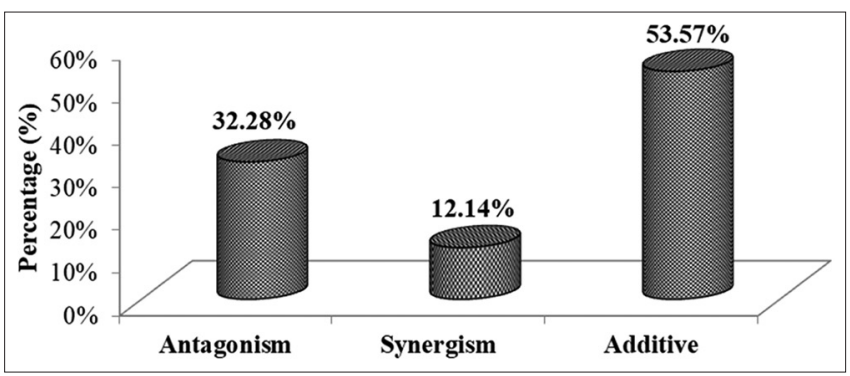

Fig. 4: Type of pharmacodynamics interaction

Among 140 PD DDIs, 75 (53.57\%) were additive, 48 (32.28\%) were antagonistic, and 17 (12.14\%) were synergistic interactions (Fig. 4).

\section{DISCUSSION}

In our study, the male population shown more drug interactions than the female population, it may be due to the fact that more hospital admissions were seen in male patients. Similar results were obtained in a study [14], and they state it is due to the early detection of common 
disorders in male patients. However, another study [15] shows that the female population was found with more drug interactions because in their study center more number of female patients were diagnosed with more diseases than males. The study shows that more commonly occurring neurological disorder is a stroke; hypertension is the leading cause of stroke, smoking habit in male patients enhances the risk of stroke in male patients, which is similar to the study [16].

According to our study, most of the patients were of age group between 60 and 70 years. As people get aged, the amount of water in the body decreases as well as the amount of fat tissue relative to water increases. Furthermore, the kidney efficiency to excrete drugs through urine and metabolism by the liver get decreased. A study [14] reported that the majority of patients were aged above 51 years and were followed by other age groups, whereas, a study [17] reported an age group of 60-70 years. Older people are at high risk of developing an ADR due to PDDI for several reasons.

The study reveals that $56.25 \%$ of cases reported are having a hospital stay of 4-6 days. In another study [18] which showed that the majority of the cases, the number of hospital stay was more than 7 days. The likelihood of getting the multiple drugs increases with the increased length of hospital stay which, in turn, will increase the likelihood of PDDIs. Another study [19] revealed that 380 (72.53\%) cardiac, $275(64.70 \%)$ neurology of patients and reported that the number of days hospital stay was between 4 and 6 days.

In our study, $41.9 \%$ cases have more than 7 drugs prescribed in the neurology department; whereas $62 \%$ cases were reported to be prescribed with more than 8 medications in the study which was conducted [20] in the neurology department [21]. The concurrent use of three or more drugs increases the risk of ADE's by 9.8 times; they stated that more the number of medications prescribed, the more the possibility of irrational polypharmacy. In our study, we found that male patients were higher in number when compared to female patients, which were similar to the study [8]. Another study [14] which also reported that male patients were higher $(70.4 \%)$ when compared to female patients. The most common interacting pair was found to be aspirin-clopidogrel; which is a major PD interaction, with a frequency of 67. This interacting pair increases the risk of bleeding due to their additive effects which are managed by monitoring of blood counts. This is similar to the study [22] in which most common interacting pair was identified as aspirin-clopidogrel. Another study [8] which is quite different from this study; clopidogrel-omeprazole was identified as the most common interacting pair.

The highest percentage of PDDI; in stroke (aspirin + clopidogrel) is $24.78 \%$, in epilepsy (carbamazepine + phenytoin and clobazam + carbamazepine) is 9.32\%, in Parkinson's disease (clonazepam + theophylline) is 2.50\%, and in Alzheimer's disease is $22.72 \%$. The total number of PDDI and the prevalence of 196 , out of 320 patients, were found to be 450 and $61.25 \%$, respectively. A similar study [23] in the department of neurology showed that the prevalence rate of PDDI was $71.6 \%$ among the patients. In our study, the prevalence of PDDIs was more in moderate severity (45.11\%). Similarly, Lubinga and Uwiduhaye [12] reported 72\% PDDIs were moderate severity, and $20 \%$ were observed to be major in severity. Another study [24] reported that $35 \%$ is of major severity, which is contrasted with the other studies. Out of 320 cases, there were 72 interacting pairs identified during the study. Among 450 PDDIs, 268 (59.55\%) were due to PK interactions, 140 (31.13\%) were due to PD interactions, 8 (1.77\%) showing both PK and PD, and 34 (7.55\%) were of unknown mechanism.

Among 268 PK DDIs, 228 (85.07\%) were due to metabolism, which is in contrast with a study [24] where the majority of interactions were due to absorption. Among 140 PD DDIs, 75 (53.57\%) were due to additive effects which are in contrast with the study [25] where $67.44 \%$ were synergistically followed by $30.7 \%$ antagonistic.

\section{CONCLUSION}

Our study concluded that the overall incidence of PDDIs was very high in the neurology department. It was found that the incidence of PDDIs was associated with older age, male gender, number of medication given and increased lengths of hospital stay. To reduce PDDIs, the number of medications for the patients should be properly controlled, and it is recommended to eliminate all medications without therapeutic benefit, the goal and indication.

Pharmacists must take responsibility for monitoring drug interactions and notifying the physician and patient about potential problems. After completion of the study, it was observed that there was an alarming rate of DDIs. Knowledge of such predictable or possible interactions is necessary for their timely detection and prevention of associated morbidity.

\section{AUTHOR'S CONTRIBUTIONS}

I would like to thank our guide Dr. R. Kameswaran for helped us for during research work and thank our Pharmacy Practice Department faculties.

\section{CONFLICTS OF INTEREST}

There are no conflicts of interest among the authors.

\section{REFERENCES}

1. Astrand B, Astrand E, Antonov K, Petersson G. Detection of potential drug interactions-a model for a national pharmacy register. Eur J Clin Pharmacol 2006;62:749-56.

2. Ahmad A, Khan MU, Haque I, Ivan R, Dasari R, Revanker M, et al. Evaluation of potential drug-drug interactions in general medicine ward of teaching hospital in Southern India. J Clin Diagn Res 2015;9:FC10-3.

3. Becker ML, Kallewaard M, Caspers PW, Visser LE, Leufkens HG, Stricker BH, et al. Hospitalisations and emergency department visits due to drug-drug interactions: A literature review. Pharmacoepidemiol Drug Saf 2007; 16:641-51

4. Delafuente JC. Understanding and preventing drug interactions in elderly patients. Crit Rev Oncol Hematol 2003;48:133-43.

5. Namazi S, Pourhatami S, Borhani-Haghighi A, Roosta S. Incidence of potential drug-drug interaction and related factors in hospitalized neurologicalpatientsintwoIranianteachinghospitals. IranJMedSci2014; 39:515-21.

6. Gourie-Devi M. Epidemiology of neurological disorders in India: Review of background, prevalence and incidence of epilepsy, stroke, Parkinson's disease and tremors. Neurol India 2014;62:588-98.

7. Shahabudin S, Bharti C, Faizal P. Surveillance of the potential drugdrug interactions in the medicine department of a tertiary care hospital. J Clin Diag Res 2012;6:1258-61.

8. Kashyap M, D’Cruz S, Sachdev A, Tiwari P. Drug-drug interactions and their predictors: Results from Indian elderly inpatients. Pharm Pract (Granada) 2013;11:191-5.

9. Bose D, Sushma M. Pattern and predictors of drug-drug interactions among the patients admitted in neurology at a tertiary care hospital-a cross-sectional study. Int J Pharm Sci Res 2016;7:3458-64.

10. Fuster V, Rydén LE, Asinger RW, Cannom DS, Crijns HJ, Frye RL, et al. ACC/AHA/ESC guidelines for the management of patients with atrial fibrillation: Executive summary A report of the American college of cardiology/American heart association task force on practice guidelines and the European society of cardiology committee for practice guidelines and policy conferences (Committee to develop guidelines for the management of patients with atrial fibrillation) developed in collaboration with the North American society of pacing and electrophysiology. Circulation 2001;104:2118-50.

11. Schedlbauer A, Prasad V, Mulvaney C, Phansalkar S, Stanton W, Bates DW, et al. What evidence supports the use of computerized alerts and prompts to improve clinicians' prescribing behavior? J Am Med Inform Assoc 2009; 16:531-8

12. Lubinga SJ, Uwiduhaye E. Potential drug-drug interactions on inpatient medication prescriptions at Mbarara regional referral hospital (MRRH) in Western Uganda: Prevalence, clinical importance and associated factors. Afr Health Sci 2011;11:499-507.

13. Venkateswaramurthy N, Krishnaveni K, Freeda RM, Kumar RS. 
Assessment of potential drug-drug interaction in stroke patients. Int $\mathrm{J}$ Pharm Pharm Sci 2016;8:221-4.

14. Katon W, Cantrell CR, Sokol MC, Chiao E, Gdovin JM. Impact of antidepressant drug adherence on comorbid medication use and resource utilization. Arch Intern Med 2005;165:2497-503.

15. Mantia G, Provenzano G. Rilevanza clinica delle interazioni farmacologiche di tipofarmacocinetico. Acta Med Mediterr 2008; 24:23-7.

16. Krishna G, Moton A, Ma L, Medlock MM, McLeod J. Pharmacokinetics and absorption of posaconazole oral suspension under various gastric conditions in healthy volunteers. Antimicrob Agents Chemother 2009;53:958-66.

17. Mirosevic Skvrce N, Macolic Sarinic V, Mucalo I, Krnic D, Bozina N, Tomic S, et al. Adverse drug reactions caused by drug-drug interactions reported to Croatian agency for medicinal products and medical devices: A retrospective observational study. Croat Med J 2011;52:604-14.

18. Ogawa R, Echizen H. Drug-drug interaction profiles of proton pump inhibitors. Clin Pharmacokinet 2010;49:509-33.
19. Kameswaran R, Rajagopal SS, Kandasamy K, Krishnan K. pharmacist intervention on identification of drug interactions in tertiary care hospitals. Int J Pharm Pharm Sci 2018;10:23-9.

20. Ismail M. Drug-food interactions and role of the pharmacist. Asian J Pharm Clin Res 2009;2:81-91

21. Bokor-Bratić M, Brkanić T. Clinical use of tetracyclines in the treatment of periodontal diseases. Med Pregl 2000;53:266-71.

22. Ogawa R, Echizen H. Clinically significant drug interactions with antacids: An update. Drugs 2011;71:1839-64.

23. Seedher N, Agarwal P. Effect of metal ions on some pharmacologically relevant interactions involving fluoroquinolone antibiotics. Drug Metabol Drug Interact 2010;25:17-24.

24. Scaldaferri F, Pizzoferrato M, Ponziani FR, Gasbarrini G, Gasbarrini A. Use and indications of cholestyramine and bile acid sequestrants. Intern Emerg Med 2013;8:205-10.

25. Phillips WA, Ratchford JM, Schultz JR. Effects of colestipol hydrochloride on drug absorption in the rat II. J Pharm Sci 1976; 65:1285-91. 